\title{
A inserção da biblioteca universitária na sociedade contemporânea: uma investigação nos serviços prestados por um Sistema de Bibliotecas
}

\author{
Jorge Santa Anna \\ Universidade Federal de Minas Gerais, Escola de Ciência da Informação, Belo Horizonte, MG, Brasil \\ jorjao20@yahoo.com.br
}

DOI: https://doi.org/10.26512/rici.v13.n1.2020.22916

Recebido/Recibido/Received: 2019-02-13

Aceitado/Aceptado/Accepted: 2019-12-02

Resumo:Traz à baila discussões acerca dos reflexos acometidos em um Sistema de Bibliotecas Universitárias à luz das transformações sociais. Objetiva identificar se a biblioteca universitária está ou não inserida e adequando-se à sociedade contemporânea, refletindo acerca de seu papel na prestação de serviços de informação, e as funções que lhe podem ser atribuídas, sobretudo com a adesão aos recursos digitais. Discorre sobre as principais características da contemporaneidade e suas interferências nas bibliotecas universitárias, destacando os serviços que podem ser realizados. Metodologicamente, o estudo caracteriza-se como qualitativo, na forma de um estudo de caso, com o uso de entrevista ao gestor do Sistema de Bibliotecas, utilizando-se, também, da pesquisa documental e bibliográfica.A partir dos resultados, concluiu-se que o Sistema de Bibliotecas analisado neste estudo vem se adequando às tendências atuais, oferecendo serviços diversificados, desde atendimento personalizado e presencial a serviços de capacitação e atendimento em ambiente digital. Portanto, constatou-se a ampliação dos serviços, considerando as necessidades dos usuários, assim como as potencialidades oriundas a partir da incorporação das tecnologias digitais nas práticas bibliotecárias. Essa constatação atende a uma das dimensões da sociedade contemporânea, o foco na prestação de serviços. Com efeito, aferiu-se que a biblioteca universitária está inserida e se adequando a esse novo contexto, embora a função educativa seja a que mais prevaleça, e a sofisticação dos serviços - em conformidade com tendências internacionais - ainda manifeste-se como um processo incipiente.

Palavras-chave: sociedade contemporânea. biblioteca universitária. serviços informacionais. prestação de serviços.

La inserción de la biblioteca universitaria en la sociedad contemporánea: una investigación sobre los servicios prestados para un Sistema de Bibliotecas

Resumen: Trae discusiones sobre los reflejos afectados en un Sistema de Bibliotecas Universitarias a la luz de las transformaciones sociales. Su objetivo es identificar si la biblioteca universitaria está insertada o no y se está adaptando a la sociedad contemporánea, reflexionando sobre su papel en la prestación de servicios de información y las funciones que se le pueden atribuir, especialmente con la adhesión a los recursos digitales. Discute las principales características de la contemporaneidad y su interferencia en las bibliotecas universitarias, destacando los servicios que se pueden realizar. Metodológicamente, el estudio se caracteriza por ser cualitativo, en forma de estudio de caso, con el uso de entrevistas con el administrador del Sistema de la Biblioteca, también utilizando investigación documental y bibliográfica. A partir de los resultados, se puede concluir que el Sistema de Bibliotecas analizado en este estudio se ha estado adaptando a las tendencias actuales, ofreciendo servicios diversificados, desde servicios personalizados y presenciales hasta servicios de capacitación y asistencia en un entorno digital. Por lo tanto, se encontró la expansión de los servicios, considerando las necesidades de los usuarios, así como 
el potencial derivado de la incorporación de tecnologías digitales en las prácticas de la biblioteca. Este hallazgo aborda una de las dimensiones de la sociedad contemporánea, el enfoque en la prestación de servicios. De hecho, parece que la biblioteca de la universidad se inserta y se adapta a este nuevo contexto, aunque la función educativa es la más frecuente y la sofisticación de los servicios, de acuerdo con las tendencias internacionales, todavía se manifiesta como un proceso incipiente.

Palabras clave: sociedad contemporánea. biblioteca universitaria. servicios informativos. prestación de servicios.

\section{The insertion of the university library in contemporary society: an investigation into the services provided for a Library System}

Abstract: It brings up discussions about the reflexes affected in a University Library System in the light of social transformations. It aims to identify whether the university library is inserted and adapting to contemporary society, reflecting on its role in providing information services, and the functions that can be attributed to it, especially with the adherence to digital resources. It discusses the main characteristics of contemporaneity and their interference in university libraries, highlighting the services that can be performed. Methodologically, the study is characterized as qualitative, in the form of a case study, with the use of interviews with the library system manager, also using documentary and bibliographic research. From the results, it can be concluded that the Library System analyzed in this study has been adapting to current trends, offering diversified services, from personalized and face-toface service to training and attendance services in a digital environment. Therefore, it was found the expansion of services, considering the needs of users, as well as the potential arising from the incorporation of digital technologies in library practices. This finding addresses one of the dimensions of contemporary society, the focus on service delivery. Indeed, it appears that the university library is inserted and adapting to this new context, although the educational function is the most prevalent, and the sophistication of services - in accordance with international trends - still manifests itself as an incipient process. .

Keywords: contemporary society. academic library. informational services. provision of services.

\section{Introdução}

É comum encontrar na literatura diversos trabalhos que versam sobre a participação e contribuição da instituição biblioteca no desenvolvimento da sociedade (CUNHA, 2003; MORIGI; PAVAN, 2004; NUNES; CARVALHO, 2016; RACHE; VARVAKIS, 2006; SANTA ANNA, 2018; SUAIDEN, 2000, dentre outros). Esses estudos também discorrem acerca das transformações que devem ser realizadas na política que sustenta essas instituições, redefinindo produtos e serviços oferecidos, haja vista permitir a adaptação e permanência dessa instituição na sociedade contemporânea.

No âmbito das bibliotecas universitárias, as transformações ocorridas na sociedade devem ter reflexos consideráveis nessas instituições. Isso porque esse tipo de biblioteca se destina a atender diferentes demandas, fornecendo atividades variadas que comunguem dos mesmos objetivos da universidade, e, dessa forma, estabelecer vínculos com a sociedade, de modo a formar profissionais adequados à realidade do contexto social. 
As bibliotecas universitárias brasileiras, nos últimos anos, ainda que atravessem muitos problemas, sobretudo os relacionados à escassez de recursos tecnológicos e de estudos voltados às necessidades da comunidade usuária, vêm se adequando às tendências atuais, com recursos de ponta e com capacidade de integração. O uso de aplicativos móveis, por exemplo, é uma estratégia que tende a contribuir com o desenvolvimento da biblioteca, ao reunir conteúdos adaptados num ambiente digital dinâmico (VIERA; VARVAKIS; FORESTI, 2017).

Com a evolução da tecnologia e a utilização de ferramentas informatizadas, a biblioteca universitária torna-se ainda mais inovadora, por meio de uma postura interventiva e ampliando sua produtividade, graças à expansão de suas potencialidades, junto à comunidade interna (universidade) quanto externa (região estadual ou municipal onde está inserida). De acordo com a pesquisa de Morigie Pavan (2004, p. 117, grifo nosso) "[...] a utilização de tais tecnologias cria e recria novas formas de interação, novas identidades, novos hábitos sociais, enfim, novas formas de sociabilidade $[\ldots] "$.

Portanto, a biblioteca universitária constitui um ambiente vivo e em integração com outros elementos, estabelecendo relações de compartilhamento e troca de informações e conhecimentos. Assim, a biblioteca está repleta de um somatório de funções aplicadas em vários segmentos sociais, sendo essas funções educativas, culturais e recreativas (QUEIROZ, 2006), além de manifestar-se, também, como um local de socialização, de relacionamento mútuo, de convivência (SANTA ANNA, 2018); um espaço que produz e consome cultura (SANCHES; RIO, 2010).

Mesmo diante dessas múltiplas funções atribuídas às bibliotecas na modernidade, segundo Santa Anna, Calmon e Campos (2016), a maioria das atividades realizadas contempla a elaboração de produtos no âmbito da organização de acervos bibliográficos. Para Souza (1996), embora venham se evoluindo, é comum encontrar, nas bibliotecas, paradigmas direcionados ao tratamento e à custódia de documentos, o que confere a essa instituição, realizar um conjunto de atividades meramente técnicas e operacionais.

Considerando a tese de Bell (1973) e de Coutinho e Lisboa (2011), de que um dos reflexos principais acometidos às instituições inseridas na sociedade contemporânea diz respeito à mudança de foco das instituições, as quais deixam de centrar na elaboração de produtos, para centrarem-se na oferta de serviços inovadores e dos mais diversificados, haja vista facilitarem a produção de conhecimento e a aprendizagem, pergunta-se: que serviços a biblioteca universitária oferece (ou poderia oferecer) a seus diversificados públicos? Essa instituição oferece serviços variados, conforme a multiplicidade de tendências do mundo 
atual? Pode-se dizer, em linhas gerais, que essa unidade está inserida e adequada à sociedade contemporânea?

Sendo assim, este estudo objetiva identificar se a biblioteca universitária está ou não inserida e adequando-se à sociedade contemporânea, refletindo acerca de seu papel na prestação de serviços de informação, e as funções que Ihe podem ser atribuídas, sobretudo com a adesão aos recursos digitais.

O estudo discorre acerca das principais características da sociedade contemporânea e as interferências dessas mudanças nas bibliotecas universitárias, destacando os serviços que podem ser realizados a partir dessas transformações e com o uso de tecnologias sofisticadas.

A pesquisa apresenta-se, metodologicamente, como um estudo de caso, sendo investigada a realidade de um Sistema de Biblioteca Universitária. Utiliza abordagem qualitativa, mediante a aplicação de entrevista ao gestor desse Sistema. Também analisa documento interno da instituição e a literatura em vigor sobre o assunto, o que caracteriza a pesquisa como de caráter documental e bibliográfico.

\section{Bases teóricas do estudo}

Dentre os estágios evolutivos no contexto das civilizações, observa-se a delimitação de três elementos que subsidiaram as atividades sociais: a agricultura, que viabilizou o despertar da Sociedade Agrícola;a indústria, em que o foco das atenções esteve na produção em larga escala por meio do trabalho fabril; e, por fim, a informação, recurso que viabiliza instrução, conhecimento e formação de competências nos indivíduos. Cada um desses elementos é considerado, respectivamente, a base que fomentou a Sociedade Agrícola, típica do período antigo e medieval; a Sociedade Industrial, consolidada no século XVIII com a revolução das máquinas; e a Sociedade Pós-Industrial, iniciada no final do século XX,tendo como eixo central o avanço e utilização das novas tecnologias nos fazeres sociais (BELL, 1973).

Essa última tem se evoluído em paralelo com a expansão dos recursos tecnológicos, o que possibilitou o surgimento de uma sociedade sustentada pela informação, cujo propósito é agregar valor para a produção de novos conhecimentos e garantir a estabilidade das instituições, em um mercado altamente competitivo. Nesse contexto, a informação e o conhecimento são molas propulsoras que possibilitam o compartilhamento do que é produzido, gerando práticas de aprendizagem (COUTINHO; LISBÔA, 2011).

O grande diferencial da sociedade atual é a instabilidade provocada no mercado, a qual redimensiona os elementos sociais, como as organizações, a se reconfigurarem, por meio de posturas interventivas e inovadoras, haja vista tornarem-se cada dia mais competitivas (BELL, 1973). 
Para o autor supracitado, a referida sociedade tem como referência o conhecimento teórico, que constitui também uma fonte de inovação, a qual será utilizada para melhorar a qualidade da produtividade da organização. As organizações devem investir em estratégias que as tornem reconhecidas, de modo que haja fidelização da clientela, por meio da prestação de serviços e produtos em consonância com as necessidades dos consumidores.

Dentre as diversas dimensões contempladas nesse atual estágio da sociedade, de acordo com as teorias de Bell (1973), as mudanças estratégicas colocam-se a serviço de melhorar a relação com os clientes, assim como ampliam a capacidade econômica da empresa. Em nível econômico, as organizações devem abandonar o modelo industrial pautado na divisão do trabalho e na mão de obra especializada, com o uso de máquinas pesadas, para, mediante o uso de tecnologias de ponta, ampliarem e diversificarem sua produtividade, considerando, principalmente, a prestação de serviços aos clientes.

Percebe-se, portanto, que na realidade atual, a organização tornou-se um espaço competitivo e inovador, substituindo os fazeres técnicos e operacionais, por práticas colaborativas de aprendizado, tendo a informação como insumo que gera conhecimento e possibilita a ampliação de competências nos colaboradores da instituição. Portanto, o modelo padrão de produção, focado na geração de produtos em alta escala, é substituído pelo fator qualidade, em que não são oferecidos produtos, mas também serviços dos mais diversificados (BELL, 1973).

Com efeito, a informação, a qualidade e a prestação de serviços são características balizares da sociedade contemporânea, ao contrário da sociedade industrial, cuja preocupação principal estava centrada na capacitação do trabalhador na operacionalização de máquinas, tendo em vista aumentar a produtividade. Assim,

[...] no âmbito do mercado, o acesso à informação visa à geração de vantagem competitiva sobre a concorrência, descoberta de novos nichos de consumidores; pesquisa e desenvolvimento de novos produtos e serviços, bem como o monitoramento do ambiente externo, a fim de identificar ameaças e/ou novas oportunidades de negócios para as empresas que 0 compõem (FERREIRA, 2003, p. 36, grifo nosso).

Os produtos e serviços oferecidos devem se adentrar a características específicas, cujo objetivo seja chamar a atenção do cliente. Para Taylor (1986), a qualidade da produção de uma empresa está relacionada à capacidade que os processos de trabalho viabilizaram quanto à agregação de valor ao produto que será disponibilizado aos consumidores. Segundo esse autor, agregar valor a produtos e serviços significa imprimir aos mesmos uma diferenciação que os tornem mais atraentes, quer seja em termos de qualidade, rapidez, durabilidade, assistência ou preço. 
No entendimento de Lucci (2016), a sociedade contemporânea é fruto da sociedade anterior, pautada na indústria e seus processos mecanizados de trabalho. Para a referida autora, o momento atual é consequência de três grandes fatores ou acontecimentos, desencadeados pelo fenômeno da industrialização, quais sejam: o aumento da vida média da população, o desenvolvimento tecnológico e a difusão da escolarização e da mídia.

Tal autora corrobora com Bell (1973) ao mencionar que, ao contrário da Sociedade Industrial, no período contemporâneo, o foco dessa sociedade está nos serviços. Segundo Lucci (2016), o setor de serviços, nos últimos anos, absorveu cerca de $60 \%$ da mão-de-obra total, mais que a indústria e a agricultura juntas, pois o trabalho intelectual é muito mais frequente que o manual, e a criatividade é mais importante que a simples execução de tarefas.

Na Sociedade Industrial, as atividades requeridas pelas indústrias giravam em torno da padronização das mercadorias e a especialização do trabalho. Ao contrário, na atual sociedade, “[...] o que conta é a qualidade de vida, a intelectualização e a desestruturalização do tempo e do espaço, ou seja, fazer uma mesma coisa em tempos e lugares diferentes (simultaneidade) [...]" (LUCCl, 2016, não paginado).

Acerca da ampliação e diversificação dos serviços na sociedade contemporânea, Rache e Varvakis (2006, p.131) descrevem que as transformações da economia mundial "[...] proporcionaram o aumento do consumo de bens e serviços em uma sociedade global, na qual o setor de serviços passou a ocupar espaço bastante significativo na economia, participando da geração de renda dos países e, consequente, criação de empregos".

Dialogando com Gianesi e Corrêa (1996), Rache e Varvakis (2006) mostram que um serviço, seja ele de qualquer natureza, apresenta características específicas, como: intangibilidade, simultaneidade, participação dos clientes e variabilidade. No contexto das bibliotecas, os autores refletem que:

[Essas características] permitem ver a biblioteca como uma organização de serviços que subsiste quando valoriza essa vivência. Isso se evidencia em serviços como o de referência, nos quais os recursos humanos e os usuários interagem em um processo. $O$ usuário é um elemento ativo no processo de produção do serviço, dessa forma, vivenciando e influenciando seu desenvolvimento e resultados (RACHE; VARVAKIS, 2006, p. 132, grifo nosso).

A ideia de serviço nos remete à oferta de algo, sendo necessária para tal ação, a presença de dois elementos: aquele que oferece e o que consome. O consumidor ou usuário, portanto, na sociedade contemporânea, passa a ter um papel diferenciado, tendo mais valorização e os produtos e serviços são planejados e concretizados, conforme suas necessidades (RACHE; VARVAKIS, 2006). 
Nesse contexto, os serviços de informação oferecidos em bibliotecas podem ser conceituados como:

[...] algo feito por um profissional, com vistas a atender ao interagente e dar uma direção para os recursos de informações de que ele necessita. Seria uma facilitação para o alcance de resultados de uma necessidade informacional. Trata-se de atender a determinada demanda, ou seja, procurar satisfazer aos interesses de informação do interagente na temática que ele procura na unidade de informação (DUARTE et al., 2015, p. 608).

Importante reforçar que as demandas informacionais que precisam ser atendidas por meio da disponibilização dos serviços podem contemplar funções distintas, com abordagens de natureza educativa, recreativa e social, de um modo geral, conforme mencionado na literatura (QUEIROZ, 2006; SANCHES; RIO, 2010; SANTA ANNA, 2018).

Com a expansão do setor de serviços, aliados às exigências e necessidades requeridas pelos clientes, assim como os impactos oriundos com o mercado globalizado da atualidade, percebe-se que toda e qualquer organização deve revestir-se de estratégias que as tornem competitivas. Considerando que as bibliotecas são organizações que prestam, principalmente, serviços e produtos informacionais para comunidades específicas, conforme relatou Maciel e Mendonça (2006), é evidente que nesses ambientes de informação, configurem-se atividades inovadoras, sendo a produtividade bibliotecária interferida por fatores de qualidade e diversificação, seja na oferta de bens e/ou serviços.

A esse respeito, proferem Tarapanoff, Araújo Junior e Cormier (2000, p. 92, grifo nosso):

as unidades de informação (bibliotecas, centros e sistemas de informação e de documentação) foram e são, tradicionalmente, organizações sociais sem fins lucrativos, cuja característica como unidade de negócio é a prestação de serviços, para os indivíduos e a sociedade, de forma tangível (produtos impressos), ou intangível (prestação de serviços personalizados, pessoais, e hoje, cada vez mais, de forma virtual - em linha, pela Internet).

Os autores supracitados consideram o uso das tecnologias digitais como potencial inovador, haja vista consolidar uma produtividade bibliotecária mais efetiva e com alto padrão de qualidade. Para Santa Anna (2015a), as bibliotecas inserem-se no paradigma do acesso, em que o foco deve estar no usuário da informação, rompendo, dessa forma, com o paradigma da custódia, o qual se limitava à oferta, tão somente, de produtos, técnicas e metodologias para tratamento de documentos em acervos bibliográficos.

No âmbito das bibliotecas universitárias, é de se esperar que essas transformações têm se apresentado com maior intensidade, haja vista as peculiaridades dessas unidades, as quais devem oferecer materiais informacionais para diferentes públicos inseridos no ambiente 
universitário, considerando as atividades de ensino, de pesquisa e de extensão (BEM et al., 2013).

Além disso, a biblioteca universitária é um organismo que se coloca a serviço do aprendizado (FERREIRA, 1980), o que pressupõe sua relação com a formação ou instrução direcionada a seus usuários, os quais constituirão a massa trabalhadora que sustentará o mercado de trabalho na sociedade contemporânea (SANTA ANNA, 2015b).

Nessa seara, as bibliotecas universitárias, em especial, precisam adaptar-se rapidamente aos novos desafios advindos das contínuas mudanças, de forma a redefinir seus papéis, priorizando suas funções e assumindo uma postura inovadora a fim de se manterem competitivas no mercado. Nesse âmago, caberá aos profissionais que as gerenciam buscar embasamento teórico, metodológico e pragmático, a fim de que possam planejar, decidir e agir, assistindo não apenas o momento presente, mas no intuito de prever tendências e necessidades futuras (NUCl et al., 2000).

A princípio, a informatização dos acervos, iniciada no final do século $X X$, é uma iniciativa essencial para ampliar o acesso às fontes de pesquisa, rompendo limitações de tempo e de espaço. Sendo assim, diferentes coleções podem ser disponibilizadas em plataformas com recursos variados para acesso, e agrupando fontes de informação de vários gêneros, como os portais de periódicos, os repositórios de trabalhos acadêmicos, dentre outros. Tais ambientes não podem ser estáticos, e precisam ser acessados a qualquer lugar, pelos usuários, sobretudo com o uso de telefonia móvel, que é, na sociedade contemporânea, uma tendência emergente. Portanto, "as bibliotecas universitárias estão oferecendo cada vez mais seus serviços por meio de aplicações telefônicas e também criando páginas da web que são acessadas por telefones celulares [...]" (CHAPUTULA; MUTULA, 2018, p. 271, tradução nossa).

No âmbito de Brasil, estudo desenvolvido por Viera, Varvakise Foresti (2017, p. 19) constatou que, embora as bibliotecas brasileiras estejam se adequando, no que tange aos dispositivos móveis, atuando de várias formas para atender a nova demanda móvel, "[...] é necessário atenção e ação na conversão dos serviços para criar novo modelo de relacionamento com os usuários baseado na mobilidade e ubiquidade".

Acerca das inovações desencadeadas pelo uso de tecnologias diferenciadas e inovadoras, Morigi e Pavan (2004) afirmam que "[...] os impactos sobre serviços interpessoais tradicionais desaparecem com a automação, provocando em decorrência o surgimento de novos serviços $[. . .]^{\prime \prime}$. Segundo esses autores, não resta dúvida de que, ao empregar as tecnologias de informação e comunicação, as bibliotecas universitárias criaram novos serviços e aperfeiçoaram os já oferecidos. 
Com a adesão às tecnologias digitais, é possível ampliar a oferta de serviços, congregando a mistura entre serviços tradicionais, realizados de modo presencial, e serviços oferecidos nos ambientes digitais, com destaque os serviços de atendimento (referência) e os serviços de divulgação. Desse modo, no âmbito acadêmico, "[...] a biblioteca objetiva garantir que professores, alunos e outros usuários tenham acesso a uma ampla e diversificada gama de recursos acadêmicos e engajando-se na divulgação para a comunidade [...]" (BARRETT, 2010, p. 308, tradução nossa). Ademais, é uma essência da biblioteca universitária, “[...] o desejo por parte de ambos, organização e pessoas, a se ajudarem, em que os alunos encontram, acessam, avaliam e usam informações [...]" (PELLEGRINO, 2012, p. 272, tradução nossa).

Nesse contexto de inovações tecnológicas, a biblioteca universitária busca a formação de diversos canais de comunicação e interação com sua clientela, com base nas tendências emergentes da atual sociedade. Os serviços de marketing e uso do acervo, por exemplo, podem ser realizados por meio do envio de mensagens instantâneas, as quais visam fornecer respostas imediatas a perguntas on-line, além de ajudar a melhorar a igualdade de acesso aos serviços da biblioteca, independentemente de o usuário estar fisicamente na biblioteca ou não. Ao oferecer serviços variados, com formatos diferentes, a biblioteca institui o modelo dinâmico, flexível e híbrido (BARRY et al., 2010).

No âmbito do uso do acervo, destaca-se a necessidade de as bibliotecas investirem na oferta de treinamentos que possibilitem o domínio das ferramentas de pesquisa, como também estimulem a competência informacional no uso das fontes. A capacitação do usuário poderá ocorrer por meio de programas de formação ministrados de modo presencial, como também, a disponibilização de tutoriais eletrônicos nos websites das bibliotecas (SLEBODNIK; RIEHLE, 2011).

Os auxílios prestados nas consultas não podem se limitar, tão somente, ao tradicional balcão de referência. Segundo Anderson et al. (2015), instituir pontos de atendimento descentralizado, que permitam uma comunicação imediata é um fazer estratégico dos bibliotecários. Para Eze (2016), as ferramentas da web 2.0 contribuem para aprimorar os websites e garantir uma aproximação mais dinâmica e interativa com os usuários. Ainda segundo essa autora, podem ser criados com uso dessas tecnologias os seguintes serviços de referência: SMS, chat, e-mail, videoconferência, web formulário etc.

No intuito de ampliar os serviços de interação com os usuários, considerando-se o potencial das ferramentas digitais, destaca-se o uso das redes sociais, as quais podem ser estruturadas para as consultas ao acervo e manifestem-se como estratégia de divulgação do que a unidade tem a oferecer à comunidade. Os sites de redes sociais ganharam gradualmente uma parte importante do tempo nas rotinas diárias das pessoas. Inúmeros sites de redes 
sociais surgiram, como Twitter, Facebook, MySpace e Linkedln, cuja intenção é permitir que a biblioteca vá ao encontro das pessoas, conforme os recursos mais utilizados por elas no cotidiano (VASSILAKAKI; GAROUFALLOU, 2015).

Queiroz (2006) lembra a necessidade de esses ambientes oferecerem produtos e serviços que estejam em consonância com as necessidades dos usuários, tendo as tecnologias infocomunicacionais como principais recursos a serem utilizados para ampliar as possibilidades de acesso e uso à informação. Mas, as atividades bibliotecárias, segundo essa mesma autora, não podem se limitar, apenas, à função informacional. A biblioteca universitária deve ampliar as funções que presta a seus variados públicos, de modo que sejam realizadas atividades de cunho cultural e recreativo, o que promove a consolidação da prática cidadã.

Corrobora com esse pensamento, Bem et al. (2013), para quem, a biblioteca universitária, assim como ocorre com a pública, deve colocar-se a serviço da comunidade, oferecendo produtos e serviços que atendam diferentes demandas, haja vista estabelecer uma relação de igualdade entre todos os frequentadores. As autoras também mencionam que a adequação do espaço da biblioteca, bem como a oferta de serviços e produtos devem considerar as limitações dos usuários, o que requer a adequação desses espaços àqueles que possuem necessidades especiais.

Com efeito, a partir dessas discussões, novamente, dialogamos com Rache e Varvakis (2006, p.137), quando concluem que são os serviços, na atual sociedade, que vão conferir à biblioteca uma intensa e constante dinâmica, ou seja, "[...] sua capacidade de transpor a métrica e estabilidade de seus acervos, permitindo a concretização de sua função social [...]". Essa função requer uma relação frequente e holística entre todos os elementos que compõem o contexto ou ambiência da biblioteca, ou seja, as atividades prestadas devem considerar suportes documentais, pessoal, informação, conhecimento, cultura organizacional e, principalmente, o público utilizador dos produtos e serviços biblioteconômicos.

Dentre as diversas dimensões que caracterizam a sociedade contemporânea, considerando, neste estudo, a importância da prestação de serviços para o sucesso organizacional e a inserção das organizações na atual sociedade, analisam-se, a seguir, os serviços oferecidos à comunidade acadêmica por um Sistema de Bibliotecas Universitárias, com o intuito de perceber como essas questões estão sendo tratadas pela referida unidade de informação.

\section{Materiais e métodos}

Segundo Vergara (2007), ao realizar pesquisa metodológica no contexto da Administração, uma metodologia de pesquisa, a fim de ser bem delineada e conduzida, deve ser elaborada considerando os meios e os fins a que se destina. 
Assim, considerando a proposta dessa autora, no que se refere aos fins, adota-se, neste estudo, a pesquisa descritiva, uma vez que se recorre à investigação de uma determinada realidade, qual seja, o Sistema de Bibliotecas de uma universidade.

Quanto aos meios utilizados para alcançar o objetivo proposto, sustentando-se na tese de Vergara (2007), adotou-se a pesquisa do tipo bibliográfica, documental e estudo de caso. A primeira modalidade forneceu as principais bases ou fundamentos teóricos, a partir da consulta a livros e artigos que versam sobre bibliotecas universitárias e a inserção delas na sociedade contemporânea. A pesquisa documental utilizou o regimento interno, considerado como política, que norteia os processos de trabalho e todas as atividades realizadas no Sistema. Por fim, no que se refere ao estudo de caso, realizou-se uma visita ao Sistema, sendo ela conduzida por meio de entrevista aplicada ao gestor.

Conceituando-se as metodologias acima descritas, considera-se a pesquisa bibliográfica como a seleção de material já publicado, cujos assuntos relacionem-se com a temática em apreço, servindo essas bibliografias como embasamento teórico e comparativo com os dados coletados no estudo in loco (VERGARA, 2007).

A pesquisa documental, segundo Vergara (2007, p. 48), consiste na análise de "[...] documentos conservados no interior de órgãos públicos e privados de qualquer natureza, ou com pessoas [...]". Alguns exemplos de documentos a serem investigados: registros, anais, regulamentos, circulares, ofícios, memorandos, balancetes, comunicações informais e outros (VERGARA, 2007).

Já o estudo de caso diz respeito a uma investigação empírica realizada no local onde ocorre ou ocorreu um fenômeno ou que dispõe de elementos para explicá-lo. As técnicas utilizadas nesse tipo de estudo são: entrevistas, aplicação de questionários, testes e observação participante ou não (GIL, 2002).

A entrevista caracteriza-se como uma técnica de coleta de dados, cujo objetivo é levantar dados a partir de um contexto analisado, por meio da interação entre entrevistado e entrevistador, manifestando-se um processo comunicativo de troca de informações, em que informações são sanadas ao máximo possível, devido à natureza subjetiva e aberta das perguntas realizadas (GIL, 2002).

Quanto à natureza das variáveis pesquisadas, este estudo é do tipo qualitativo, uma vez que os dados não foram obtidos de um grande número de entrevistados (GIL, 2002). Assim, nesta pesquisa, os dados foram coletados, tão somente, com o uso de perguntas abertas, em entrevista realizada a um bibliotecário que ocupa o cargo de gestor do Sistema de Bibliotecas.

\section{Resultados e discussão}

A partir da análise ao regimento interno do Sistema de Bibliotecas, mediante a aplicação da pesquisa documental, identificou-se que o Sistema é composto por seis 
bibliotecas, denominadas de setoriais e uma biblioteca central. Os principais serviços oferecidos pelas unidades, tanto a Central quanto as setoriais estão relacionados, sobremaneira, ao processo de dinamização das coleções, ou seja, serviços de atendimento, referência, empréstimo, devolução, quitação de multas, dentre outros.

Analisando os objetivos da biblioteca inseridos no regimento e os serviços correspondentes para execução desses objetivos, tornar-se possível alinhar esses serviços com as funções educativa, recreativa e social (funções essas apontadas na literatura). 0 quadro 1 expõe essa correspondência.

Quadro 1 -

Objetivos, principais serviços ofertados e o alinhamento com as funções de uma biblioteca

\begin{tabular}{|c|c|c|}
\hline Objetivos da biblioteca & Principais serviços oferecidos & Função \\
\hline $\begin{array}{l}1 \text { - congregar, selecionar, processar e disseminar a } \\
\text { documentação necessária aos programas de ensino, pesquisa } \\
\text {,extensão e administração das unidades que integram a } \\
\text { universidade }\end{array}$ & $\begin{array}{l}\text { - Serviços de referência } \\
\text { - Treinamento no uso do acervo }\end{array}$ & - Educativa \\
\hline $\begin{array}{l}2 \text { - ser depositária da produção intelectual e científica da } \\
\text { comunidade universitária, das publicações da própria } \\
\text { universidade e de outras que garantam preservar, conhecer e } \\
\text { difundir a evolução cultural, artística, científica e histórico- } \\
\text { administrativa da universidade }\end{array}$ & $\begin{array}{l}\text { - Catalogação na fonte } \\
\text { - Depósito de trabalhos na BDTD } \\
\text { - Depósito de documentos no } \\
\text { repositório institucional }\end{array}$ & $\begin{array}{l}\text { - Educativa } \\
\text { - Social }\end{array}$ \\
\hline $\begin{array}{l}3 \text { - proporcionar serviços de bibliografia, de comutação e de } \\
\text { informação aos professores, pesquisadores, servidores técnico- } \\
\text { administrativos e estudantes, garantida a maximização no uso } \\
\text { dos recursos informacionais existentes. }\end{array}$ & $\begin{array}{l}\text { - Catalogação na fonte } \\
\text { - Empréstimo entre bibliotecas } \\
\text { - Comutação bibliográfica } \\
\text { - Treinamento no uso do acervo } \\
\text { - Visitas guiadas } \\
\text { - Serviço de referência }\end{array}$ & - Educativa \\
\hline
\end{tabular}

Fonte: Dados da pesquisa (2018).

Percebe-se que a função educativa prevalece na oferta dos serviços de informação para os usuários. Esse resultado reforça o potencial das bibliotecas universitárias no que tange ao provimento de informações para subsidiar as atividades universitárias, considerando a trindade ensino, pesquisa e extensão, de acordo com os argumentos apontados na literatura, tal como no estudo de Amboni (2013), Barry et al. (2010), Cunha (2010), dentre outros.

Ainda com base na análise ao regimento, constatou-se a divisão das bibliotecas em setores, considerando os produtos e serviços que são oferecidos em cada um, embora esses setores não estejam presentes em todas as unidades do Sistema. 0 quadro 2 apresenta 0 nome do setor, os serviços oferecidos, a biblioteca que o possui (conforme registrado no regimento) e a correspondência desses setores com as funções das bibliotecas.

Quadro 2 -

Identificação dos setores, serviços oferecidos, nome da unidade e função correspondente 


\begin{tabular}{|c|c|c|c|}
\hline Setor da biblioteca & Principais serviços & Nome da unidade & Função \\
\hline Desenvolvimento de coleções & $\begin{array}{ll} & \text { Atendimento } \\
\text { fornecedores } & \\
\text { - Pregão eletrônico } & \\
\text { - Recebimento } & \text { de } \\
\text { trabalhos acadêmicos } & \end{array}$ & - Biblioteca Central & $\begin{array}{l}\text { - Educativa } \\
\text { - Social }\end{array}$ \\
\hline Processamento técnico & $\begin{array}{l}\text { - Levantamento } \\
\text { bibliográfico } \\
\text { - Catalogação na fonte }\end{array}$ & $\begin{array}{l}\text { - Biblioteca Central } \\
\text { - Biblioteca Campus } \\
\text { Saúde }\end{array}$ & - Educativa \\
\hline Setor de Reparos & $\begin{array}{l}\text { - Pequenos reparos em } \\
\text { materiais danificados }\end{array}$ & $\begin{array}{l}\text { - Biblioteca Central } \\
\text { - Campus Agrárias }\end{array}$ & - Educativa \\
\hline Setor de multimeios & $\begin{array}{l}\text { - } \text { Atendimento a usuários } \\
\text { - Empréstimos de } \\
\text { materiais eletrônicos }\end{array}$ & $\begin{array}{l}\text { - Biblioteca Central } \\
\text { - Campus Saúde } \\
\text { - Campus Agrárias }\end{array}$ & - Educativa \\
\hline Setor de referência & $\begin{array}{l}\text { - Atendimento no balcão } \\
\text { de referência } \\
\text { - Referência digital: e- } \\
\text { mail e web formulário } \\
\text { - Redes sociais: Facebook }\end{array}$ & - Todas as bibliotecas & $\begin{array}{l}\text { - Educativa } \\
\text { - Social }\end{array}$ \\
\hline Setor de periódicos e obras raras & $\begin{array}{l}\text { - Atendimento presencial } \\
\text { - Referência digital: e- } \\
\text { mail e web formulário }\end{array}$ & - Biblioteca Central & - Educativa \\
\hline $\begin{array}{l}\text { Setor de tecnologia, repositório e } \\
\text { coleções digitais }\end{array}$ & $\begin{array}{l}\text { - Atendimento presencial } \\
\text { - Referência digital: e- } \\
\text { mail e web formulário } \\
\text { - Redes sociais: Facebook }\end{array}$ & - Biblioteca Central & - Educativa \\
\hline Setor de empréstimo & $\begin{array}{l}\text { - Atendimento presencial: } \\
\text { empréstimos, } \\
\text { renovações, } \\
\text { recebimentos de multas } \\
\text { etc. } \\
\text { - Atendimento digital: } \\
\text { renovações, reservas, } \\
\text { consultas ao acervo etc. }\end{array}$ & - Todas as bibliotecas & $\begin{array}{l}\text { - Educativa } \\
\text { - Social }\end{array}$ \\
\hline $\begin{array}{l}\text { Espaço de leitura, pesquisa e } \\
\text { auditório }\end{array}$ & $\begin{array}{l}\text { - Consulta local } \\
\text { - Eventos diversos e } \\
\text { reuniões }\end{array}$ & $\begin{array}{l}\text { - Biblioteca Central } \\
\text { - Campus Saúde }\end{array}$ & $\begin{array}{l}\text { - Educativa } \\
\text { - Recreativa } \\
\text { - Social }\end{array}$ \\
\hline
\end{tabular}

Fonte: Dados da pesquisa (2018).

Os dados constantes no quadro 2 evidenciam que a Biblioteca Central possui todos os setores, haja vista a sua maior dimensão, tanto em espaço físico, quanto na diversidade de serviços oferecidos, além dos produtos elaborados, para atendimento a outras unidades do Sistema. Embora a funções social e recreativa manifestam-se em alguns serviços prestados, a maior predominância está na função educativa, o que, novamente, reforça o foco do Sistema nas atividades acadêmicas. Essa constatação vai ao encontro da tese defendida por Accart (2012), ao considerar as bibliotecas universitárias como unidades especializadas.

Mesmo não havendo maiores detalhes a respeito dos serviços oferecidos, os dados oriundos da pesquisa documental possibilitam aferir que o Sistema de Bibliotecas vem se adequando às tendências da sociedade contemporânea, sobretudo no que tange à ampliação e 
fortalecimento dos serviços a partir do uso das tecnologias digitais, tal como o uso da referência digital e as interações estabelecidas com a comunidade via redes sociais.

Os desafios impostos pela contemporaneidade, tais como o aumento da concorrência, cortes de verbas públicas, globalização, dentre outros despertam nos bibliotecários a necessidade "[...] de se pensar estrategicamente sobre tecnologia e para ver como podem oferecer possibilidades e soluções energizantes para enfrentar esses desafios [...]". Isso coloca as bibliotecas universitárias em uma situação de adaptação, cujos profissionais tornam-se aptos, por meio da tecnologia, a inovarem, melhorarem a qualidade, medir o sucesso e alinhar os serviços com as prioridades de suas organizações. Logo, "[...] com tecnologia, os bibliotecários podem se reintroduzir como visíveis, parceiros valiosos e essenciais na obtenção de objetivos comuns [...]" (ANDERSON et al., 2015, p. 222, tradução nossa, grifo nosso).

Com o intuito de fornecer uma explicação mais detalhada acerca dos serviços prestados no Sistema analisado neste estudo, fez-se necessário a entrevista junto ao gestor desse Sistema. O roteiro foi formado por perguntas abertas, considerando-se os seguintes aspectos: 1 - a função da política que norteia a unidade de informação; 2 - os serviços oferecidos no Sistema; e 3 - mudanças que foram realizadas, nos últimos anos, e quais as expectativas para o futuro.

A primeira pergunta visava investigar se os serviços oferecidos realizados estavam em consonância com as diretrizes estabelecidas pela biblioteca e, se essas estavam em sintonia com os objetivos da universidade.De acordo com o profissional entrevistado, o regulamento foi elaborado por uma equipe de bibliotecários, juntamente com membros da Reitoria que compõem o Conselho do Sistema de Bibliotecas. Esse documento foi elaborado no ano de 2000 e já passou por três modificações.

Segundo o entrevistado, a biblioteca não pode realizar nada que não esteja documentado, como também, não pode deixar de realizar nenhumas das atividades prescritas nesse documento. $\mathrm{O}$ documento está de acordo com os objetivos institucionais, tendo em vista atender diferentes públicos. No entanto, a prioridade é atribuída aos usuários que possuem vínculo com a instituição, tais como discentes, docentes e colaboradores.

Ao ser questionado se a preferência pela comunidade acadêmica não tornaria a biblioteca um espaço excludente, não se adequando, portanto, à ideia de universalização de acesso ao conhecimento, de acordo com as possibilidades promovidas com o uso da internet, o profissional defendeu a necessidade de ampliação dos serviços para públicos externos. No entanto, salienta a importância do regulamento e a necessidade de a universidade promover 
debates mais profundos acerca de se definir as prioridades institucionais, sem, contudo, excluir as necessidades sociais.

Os dados coletados com essa pergunta revelam a preocupação com as necessidades dos usuários. Como os sistemas de bibliotecas universitárias colocam-se a serviço da comunidade acadêmica, e considerando as disposições estabelecidas no regimento, não resta dúvida de que os serviços descritos devem fazer parte do cotidiano da biblioteca, juntamente com as atividades inovadoras, as quais condicionarão ganhos de competitividade para a biblioteca, inserindo-a no contexto das tendências contemporâneas, e, portanto, atendendo as demandas mais recentes.

No que tange aos serviços oferecidos, conforme pontuado na segunda pergunta, o respondente reforçou que há diversos serviços, estando eles focados, prioritariamente, nas demandas informacionais da universidade. $O$ gestor reconhece que muitos desses serviços são considerados como tradicionais, uma vez que estão relacionados, em uma situação de complementaridade, com os produtos bibliotecários. Ou seja, para que os produtos sejam gerados, faz-se necessária a consolidação de um serviço. Como exemplo, o entrevistado citou: os serviços do setor de desenvolvimento de coleções, o serviço de confecção de fichas catalográficas, serviços de levantamento bibliográfico e o serviço de conservação curativa.

Alguns serviços são compostos por um conjunto de atividades, cujo objetivo dessas atividades não é gerar um produto, mas sim oferecer benefícios para os usuários, que não se limitam à concretização de um bem material, mas algo intangível. Esse fato ilustra as características de intangibilidade, simultaneidade, participação do cliente e variabilidade inerentes à prestação de serviços no âmbito organizacional, conforme discorrido por Gianesi e Corrêa (1996) e Rache e Varvakis (2006).

Como exemplos de serviços com essas características específicas, o entrevistado cita: atendimento telefônico para tirar dúvidas com outras unidades e usuários,serviço de referência/atendimento personalizado, empréstimo entre bibliotecas, comutação bibliográfica, treinamento de usuários, capacitações a usuários e profissionais, manutenção do site da biblioteca e dos serviços informatizados,serviços de empréstimo/devolução, quitação de débitos, esclarecimento de dúvidas, dentre outros.

Nesses serviços, observa-se a relação interativa firmada entre prestador e consumidor do serviço, o que viabiliza maiores condições a respeito da percepção e necessidades dos usuários, por conseguinte, fomenta estratégias para melhoria contínua do que é oferecido à clientela, considerando o fator excelência e qualidade.

Esses fatores constituem bases fundamentais para inserção das organizações na sociedade contemporânea, como apontado nos estudos de Nunes e Carvalho (2016) e Toffler 
(2003). Para que esses fatores sejam alcançados, de acordo com Melo, Scarvada e Almeida (2015), a equipe da biblioteca precisa trabalhar a gestão de seus processos, tendo como foco o usuário e o fornecedor como partes conexas aos processos do serviço. Com essa intenção e valorizando a gestão da unidade, é possível conquistar aqueles que ainda possuem alguma resistência a mudanças, tornando-os conscientes e engajados com a oferta de serviços inovadores, diversificados, de alta qualidade e que realizem as funções designadas às bibliotecas quanto à oferta informacional (educativa, recreativa e social).

Destaca-se, também, a ampliação de serviços prestados na unidade, serviços esses que surgiram nos últimos anos, em virtude da valorização atribuída ao usuário e com a utilização das novas tecnologias. Como exemplos desses serviços, o gestor destaca: 1 - treinamentos e capacitações para colaboradores e usuários finais, sobre o uso do catálogo informatizado, bem como a consulta às bases de dados e repositórios acadêmicos; 2 - os serviços oferecidos no sítio da biblioteca, como consulta ao acervo, renovação de materiais, acesso à base de dados,serviço de tirar dúvidas e serviço de referência via canais digitais, como o e-mail; e 3 os serviços de divulgação realizados com o uso das redes sociais, com destaque à página do Facebook.

Ao longo do discurso proferido pelo respondente, foi mencionado que os serviços de informação, de um modo geral, são propagadores da mediação, colocando em sintonia usuários, acervos e recursos. Nesse contexto, o gestor esclarece que o Sistema tem priorizado essa questão. Mesmo havendo inúmeras dificuldades, sobretudo no que tange à oferta adequada de recursos humanos e materiais, os bibliotecários do Sistema têm assumido uma postura de ir ao encontro dos usuários, facilitando, dessa forma, o compartilhamento e a produção de novos sentidos, valores e conhecimentos.

A literatura tem sinalizado a importância da biblioteca universitária como ambiente de mediação, cujas pessoas que circulam nesse ambiente exercem funções essenciais na mediação informacional, mesmo com o uso de tecnologias de ponta, as quais acabam por ampliar esse processo. Com efeito, a biblioteca estimula o suprimento das necessidades informacionais dos usuários, "[...] beneficiando a troca de informações, a discussão e a construção coletiva de conhecimento [...]" (SANTOS; GOMES; DUARTE, 2014, p. 1).

Aqui dialogamos com Morigi e Pavan (2004, p. 124), ao afirmarem que, no contexto da sociedade contemporânea, "[...] em que a mediação dos significados compartilhados passa a ser realizada mediante o auxílio do computador, com a utilização das tecnologias de informação e comunicação, gera diferentes impactos, entre os quais uma nova forma de sociabilidade $[\ldots]^{\prime \prime}$. 
Os autores também consideram que a biblioteca universitária na atual sociedade deve se caracterizar "[...] pelas transformações nos processos interacionais entre os próprios bibliotecários em seus ambientes de trabalho, envolvendo novas práticas profissionais em relação às formas de gerenciamento da informação e dos serviços" (MORIGI; PAVAN, 2004, p. 124). Essas considerações descritas no estudo desses autores são percebidas no âmbito da biblioteca universitária aqui analisada, uma vez que ela oferece diferentes serviços, considerando o valor que o usuário possui, assim como utiliza as potencialidades das novas tecnologias, tendo em vista desencadear o surgimento de novas possibilidades bibliotecárias.

Ainda no âmbito da pergunta de número 2 (serviços oferecidos), questionaram-se como os serviços são avaliados e qual a participação do usuário, nesse processo. O respondente discorreu que todas as bibliotecas do Sistema precisam realizar ações avaliativas, em suas rotinas de trabalho, de modo a conceder oportunidades de ouvir a comunidade, a fim de realizar as adequações necessárias, visando a melhoria contínua. Dentre os serviços avaliativos, destacou o uso da tradicional caixas de sugestões, cujos comentários escritos podem ser deixados pelos usuários, como também, a oferta de canais de contato entre a unidade e usuários, como o e-mail e as sugestões enviadas através do software de gestão do acervo (Pergamum).

A respeito da valorização do usuário considerado como elemento principal na adequação dos serviços oferecidos, essa representa uma tendência da sociedade contemporânea e tem sido adaptada ao universo das bibliotecas universitárias. De acordo com as considerações apontadas por Baro, Efe e Oyeniran (2014, p. 524, tradução nossa, grifo nosso), "[...] a equipe da biblioteca deve primeiro examinar quem são seus usuários e suas respectivas preferências e, em seguida, desenvolver serviços de biblioteca para apoiá-los".

A última pergunta do questionário investigou acerca das mudanças que foram realizadas nos últimos anos e quais as expectativas para o futuro. De acordo com o entrevistado, as principais mudanças realizadas dizem respeito ao uso acentuado das tecnologias na oferta de produtos e, principalmente, de serviços no ambiente digital. Também destacou como atividades inovadoras, a realização dos treinamentos e as capacitações, as quais são direcionadas a usuários intermediários (os colaboradores) quanto usuários finais (demais usuários). Esses treinamentos visam a capacitar os usuários ao uso das bases de dados, bem como à gestão e manuseio do catálogo eletrônico, permitindo que os usuários possam aproveitar todas as possibilidades oferecidas pelas novas tecnologias.

Mesmo com esse reconhecimento de que o Sistema vem se adequando e se inserindo nas novas tendências, o gestor reconheceu que algumas novidades poderiam ser implementadas, mas que ainda carecem de recursos para serem operacionalizadas, tais como 
a elaboração de serviços mais dinâmicos e interativos. A consulta à literatura internacional, por exemplo, demonstra o quanto a tecnologia pode contribuir, sobretudo na ampliação dos serviços de referência, tal como o uso de telefonia móvel (CHAPUTULA; MUTULA, 2018), as ações de alfabetização informacional, seja na forma presencial, digital ou por meio dos tutorias on-line (SLEBODNIK; RIEHLE, 2011), e a elaboração de serviços mais dinâmicos e interativos (BANDYOPADHYAY; BOYD-BYRNES, 2016).

O crescimento exponencial dos recursos digitais e sua ampla aceitação entre a biblioteca e os usuários estão moldando a natureza de todos os serviços nas bibliotecas. Bibliotecas acadêmicas têm abraçado a tecnologia digital como um meio de melhorar os serviços e as coleções. Esses esforços aumentaram a eficiência dos serviços e melhoraram o acesso aos recursos para estudantes, professores, pesquisadores e outros usuários [...] (BANDYOPADHYAY; BOYD-BYRNES, 2016, p. 597, tradução nossa, grifo nosso).

No que se refere às novidades para o futuro, o entrevistado destacou o papel dinâmico que as bibliotecas universitárias devem se revestir, transformando-se em organismos em constante aperfeiçoamento, haja vista satisfazerem diferentes demandas e se tornarem instituições reconhecidas no âmbito universitário quanto no âmbito social.

Ao ser indagado sobre as múltiplas funções atribuídas a uma unidade de informação, o entrevistado considera que a biblioteca ainda deixa a desejar, mas que pretende, em um futuro próximo, elaborar projetos voltados à oferta de serviços para a comunidade externa, tendo em vista despertar a capacidade de transformação e intervenção da biblioteca no desenvolvimento da sociedade. Nas palavras do gestor do Sistema:

Ainda temos muito que fazer para que nossas práticas sejam reconhecidas como viabilizadoras de desenvolvimento social. Estamos trabalhando para que esse Sistema ofereça também serviços para a comunidade externa, sobretudo no que se refere a atividades culturais e de entretenimento, pois isso, além de servir como estratégia de marketing, certamente despertará nas pessoas o interesse pela leitura, pela instrução, logo, manifesta-se, com essas intenções, o exercício da cidadania.

Para o entrevistado, o investimento na prestação de serviços a todos os cidadãos da sociedade deve ser um dever das bibliotecas, principalmente as que são mantidas pelo poder público. Assim, conforme relatado:

O acesso à informação, ao conhecimento, ao letramento, haja vista, desenvolver a intelectualidade e o senso crítico é um direito dos cidadãos de um Estado Democrático, logo, as instituições públicas, nesses novos tempos, devem transparecer suas práticas e serviços viabilizando condições para concretização desses direitos.

Portanto, na sociedade contemporânea, a biblioteca universitária tem sua importância garantida, mediante à ampliação no oferecimento de serviços, considerando o compromisso que tem com a sociedade onde está inserida. Com efeito, é importante considerar, de acordo com Leitão (2005), que as bibliotecas universitárias no contexto em que estão inseridas devem 
atuar como agentes de disseminação da informação e prestação de serviços dos mais diversificados, passando, assim, a serem identificadas e reconhecidas como um importante elemento que traz retorno e que faz jus aos recursos nela investidos.

\section{Considerações finais}

A partir dos resultados, pode-se declarar que as bibliotecas universitárias vêm se evoluindo e se aperfeiçoando, sobretudo no que tange à ampliação dos serviços de referência os quais passam a utilizar os recursos digitais - e maior valorização do usuário, mediante a oferta de treinamento e ações de aproximação e interação desses sujeitos com os serviços e recursos que possibilitam o uso da informação.

Os dados levantados, analisados e contextualizados permitiram concluir que o Sistema de Biblioteca analisado neste estudo vem se adequando às tendências atuais, oferecendo serviços diversificados, desde atendimento personalizado e presencial a serviços de capacitação e atendimento em ambiente digital. Portanto, constatou-se a ampliação dos serviços, considerando as necessidades dos usuários, assim como as potencialidades oriundas a partir da incorporação das tecnologias digitais nas práticas bibliotecárias. Essa constatação atende a uma das dimensões da sociedade contemporânea, o foco na prestação de serviços. Com efeito, afere-se que a biblioteca universitária está inserida e se adequando a esse novo contexto.

Mesmo em face das tentativas de adequação das bibliotecas universitárias brasileiras às tendências atuais, percebeu-se que os Sistemas de Bibliotecas ainda carecem de iniciativas mais ambiciosas, no comparativo com as ações que têm sido realizadas em âmbito internacional. O aproveitamento dos recursos interativos, tal como o uso de aplicativos de dispositivos móveis, a criação de contatos imediatos entre usuários e bibliotecários, a gestão dos programas de marketing e instrução informacional, com uso das redes sociais, são algumas iniciativas incipientes no Brasil, embora já consolidadas em muitos países.

No contexto brasileiro, é provável que essas iniciativas sejam incipientes, haja vista os problemas enfrentados pelas universidades, especificamente a escassez de recursos necessários para modernização dos serviços oferecidos. Essa ocorrência pode ser um fator que inibe a concretude das funções recreativas e sociais, cuja unidade passa a ser um espaço meramente educativo, e, portanto, não atendendo plenamente as exigências da contemporaneidade. Assim, estudos futuros precisam ser realizados, a fim de comparar a realidade nacional com a internacional, e reconhecer os desafios enfrentados pelas bibliotecas universitárias brasileiras. 


\section{Referências}

ACCART, Jean-Philippe. Serviço de referência: do presencial ao virtual. Brasília: Briquet de Lemos, 2012.

AMBONI, Narcisa de Fátima (Org.). Gestão de bibliotecas universitárias: experiências e projetos da UFSC. Florianopolis: UFSC, 2013. p. 69-78.

ANDERSON, Patrícia et al. Enhancing library impact through technology. Medical Library Association, v. 103, n. 4, 2015.

BANDYOPADHYAY, Aditi; BOYD-BYRNES, Mary Kate. Is the need for mediated reference service in academic libraries fading away in the digital environment? Reference Services Review, v. 44, n. 4, p. 596-626, 2016. Disponivel em: <https://www.emeraldinsight.com/doi/full/10.1108/RSR-02-2016-0012>. Acesso em: 22 maio 2019.

BARO, Ebikabowei Emmanuel; EFE, Bueaty; OYENIRAN, Gboyega. Reference inquiries received through different channels The challenges reference librarians face in university libraries in Nigeria. Reference Services Review, v. 42, n. 3, p. 514-529, 2014. Disponível em: $<$ https://www.emeraldinsight.com/doi/full/10.1108/RSR-09-2013-0049>. Acesso em: 21 maio 2019.

BARRETT, Felicia. An analysis of reference services usage at a regional academic health sciences library. Journal of the Medical Library Association, v. 98, n. 4, out. 2010. Disponível em: <https://www.ncbi.nlm.nih.gov/pmc/articles/PMC2947131/>. Acesso em: 22 maio 2019.

BARRY, Eithne et al. Virtual Reference in UK Academic Libraries: The Virtual Enquiry Project 200809. Library Review, v. 59, n. 1, p. 40-55, 2010. Disponível em: $<$ https://www.researchgate.net/publication/235302617 Virtual reference in UK academic I ibraries The virtual enquiry project 2008-2009>. Acesso em: 21 maio 2019.

BELL, Daniel. O advento da Sociedade Pós-Industrial. São Paulo: Cultrix, 1973.

BEM, Roberta Moraes de et al. O papel da Biblioteca Universitária na vida acadêmica do estudante com deficiência: Ambiente de Acessibilidade Informacional da UFSC. In: AMBONI, Narcisa de Fátima (Org.). Gestão de bibliotecas universitárias: experiências e projetos da UFSC. Florianópolis: UFSC, 2013. p. 69-78.

CHAPUTULA, Aubrey Harvey; MUTULA, Stephen. eReadiness of public university libraries in Malawi to use mobile phones in the provision of library and information services. Library $\mathbf{H i}$ Tech, v. 36, n. 2, 2018. Disponível em: <https://www.emeraldinsight.com/doi/full/10.1108/LHT-10-2017-0204>. Acesso em: 23 maio 2019.

COUTINHO, Clara; LISBÔA, Eliana. Sociedade da informação, do conhecimento e da aprendizagem: desafios para educação no século XXI. Revista de Educação, v. 38, n. 1, p. 5-22, 2011. Disponível em: <http://revista.educ.ie.ulisboa.pt/arquivo/vol XVIII 1/artigo1.pdf>. Acesso em: 16 ago. 2019. 
CUNHA, Murilo Bastos da. A biblioteca universitária na encruzilhada. DataGramaZero, Rio de Janeiro, v. 11, n. 6, dez. 2010. Disponível em: <http://repositorio.unb.br/handle/10482/14869>. Acesso em: 2 mar. 2019.

CUNHA, Vanda Angélica da. A biblioteca pública no cenário Sociedade da Informação. Biblos, v. 4, n. 15, abr./jun. 2003. Disponível em:<http://eprints.rclis.org/5540/1/2003 014.pdf>. Acesso em: 15 abr. 2018.

DUARTE, Evandro Jair et al. Os serviços e os produtos de informação oferecidos pela Biblioteca Pública de Santa Catarina. Revista ACB: Biblioteconomia em Santa Catarina, Florianópolis, v. 20, n. 3, p. 606-620, set./dez. 2015. Disponível em: <https://revista.acbsc.org.br/racb/article/view/1100/pdf $>$. Acesso em: 20 abr. 2018.

EZE, Monica. Channels Students Prefer in Submitting Reference Inquiries: A Survey of Undergraduate Students in University of Nigeria, Nsukka. Library Philosophy and Practice, v. 13, n. 54, 2016. Disponível em: <https://digitalcommons.unl.edu/libphilprac/1354/>. Acesso em: 21 maio 2019.

FERREIRA, Lusimar Silva. Bibliotecas universitárias brasileiras: análises de estruturas centralizadas e descentralizadas. Brasília: INL, 1980.

FERREIRA, Rubens da Silva. A sociedade da informação no Brasil: um ensaio sobre os desafios do Estado. Ciência da Informação, Brasília, v. 32, n. 1, p. 36-41, jan./abr. 2003.

GIANESI, Irineu Gustavo; CORRÊA, Henrique. Administração estratégica de serviços: operações para a satisfação do cliente. São Paulo: Atlas, 1996.

GIL, Antônio Carlos. Como elaborar projetos de pesquisa. 4. ed. São Paulo: Atlas, 2002.

LEITÃO, Bárbara Júlia Menezello. Avaliação qualitativa e quantitativa numa biblioteca universitária. Niterói: Intertexto; Rio de Janeiro: Interciência, 2005.

LUCCI, Elian Alabi. A Era Pós-Industrial, a Sociedade do Conhecimento e a Educação para o Pensar. 2016. Disponível em: <http://hottopos.com/vidlib7/e2.htm>. Acesso em: 15 abr. 2018.

MACIEL, Alba Costa; MENDONÇA, Marília Alvarenga Rocha.Bibliotecas como organizações.Rio de Janeiro: Interciência; Niterói: Intertexto, 2006.

MELO, Elisete de Sousa; SCARVADA, Anniball José; ALMEIDA, Mariza. Gestão de serviços em bibliotecas e unidades de informação: revisão de literatura - 2010 A 2014. Polêmica, v. 15, n. 1, 2015. Disponível em: <https://www.epublicacoes.uerj.br/index.php/polemica/article/view/16001/12044>. Acesso em: 15 maio 2018.

MORIGI, Valdir José; PAVAN, Cleusa. Tecnologia de informação e comunicação: novas sociabilidades nas bibliotecas universitárias. Ciência da Informação, Brasília, v. 33, n. 1, p. 117125, jan./abr. 2004.

$\mathrm{NUCl}$, Elaine et al. O planejamento estratégico e os cenários de bibliotecas e serviços de informação: tendências na literatura. In: RAMOS, Maria Etelvina. Tecnologia e novas formas de gestão em bibliotecas universitárias. Ponta Grossa: UFPG, 2000. p. 127-144. 
NUNES, Martha Suzana Cabral; CARVALHO, Kátia de. As bibliotecas universitárias em perspectiva histórica: a caminho do desenvolvimento durável. Perspectivas em Ciência da Informação, Belo Horizonte, v. 21, n. 1, p. 173-193, jan./mar. 2016. Disponível em: $<$ http://portaldeperiodicos.eci.ufmg.br/index.php/pci/article/view/2572/1708>. Acesso em: 16 ago. 2019.

PELLEGRINO, Catherine. Does Telling Them to Ask for Help Work? Investigating Library HelpSeeking Behaviors in College Undergraduates. Reference \& User Services Quarterly, v. 51, n. 3, p. 272-277, 2012. Disponível em: <https://journals.ala.org/index.php/rusq/article/view/3130/3248>. Acesso em: 23 maio 2019.

QUEIROZ, Antônia Maria Carvalho de. A biblioteca, uma organização sociocultural e instrumento a serviço da educação e da cidadania. 2006. 53 f. Monografia (Especialização em Educação) - Programa de Pós-graduação em Metodologia da Educação Superior com Ênfase em Novas Tecnologias, Faculdade Batista Brasileira, Salvador, 2006.

RASCHE, Francisca; VARVAKIS, Gregório. Bibliotecas públicas e seus serviços. In: CUNHA, Mirian Vieira; SOUZA, Francisco das Chagas. Comunicação, gestão e profissão: abordagens para o estudo da Ciência da Informação. Belo Horizonte: Autêntica, 2006. p. 127-140.

SANCHES, Gisele; RIO, Sinomar Ferreira do. Mediação da informação no fazer do bibliotecário e seu processo em bibliotecas universitárias no âmbito das ações culturais. InCID, Ribeirão Preto, v. 1, n. 2, p. 103-121, jul./dez. 2010. Disponível em: <http://www.revistas.usp.br/incid/article/view/42323/45994>. Acesso em: 16 ago. 2019.

SANTA ANNA, Jorge. A biblioteca universitária e sua intervenção no contexto social: fomentando práticas multifuncionais. Revista Ibero-americana de Ciência da Informação, Brasília, v. 11, n. 2, p. 449-469, maio/ago. 2018. Disponível em: <http://www.brapci.inf.br/index.php/article/download/63933>. Acesso em: 16 ago. 2019.

SANTA ANNA, Jorge. A biblioteca universitária no presente: de labirinto à encruzilhada em busca da biblioteca híbrida. Revista ACB: Biblioteconomia em Santa Catarina, Florianópolis, v. 20, n. 1, p. 6-18, jan./abr. 2015b. Disponível em: $<$ http://revista.acbsc.org.br/racb/article/view/982/pdf 117>. Acesso em: 10 abr. 2018.

SANTA ANNA, Jorge. Trajetória histórica das bibliotecas e o desenvolvimento dos serviços bibliotecários: da guarda informacional ao acesso. Revista Digital de Biblioteconomia e Ciência da Informação, Campinas, v. 13, n. 1, p.138-155, jan./abr. 2015a.

SANTA ANNA, Jorge; CALMON, Maria Aparecida; CAMPOS, Suelen de Oliveira.

Representação documentária em diferentes bibliotecas: o tratamento informacional como um processo plural. Revista ACB: Biblioteconomia em Santa Catarina, Florianópolis, v. 21, n. 1, p. 61-75, dez./mar. 2016.

SANTOS, Raquel do Rosário; GOMES, Henriette Ferreira; DUARTE, Emeide Nóbrega. O papel da biblioteca universitária como mediadora da informação para construção de conhecimento coletivo. DataGramaZero: Revista de Informação, Rio de Janeiro, v. 15, n. 2, abr. 2014. Disponível em: <http://www.brapci.inf.br/index.php/res/download/45947>. Acesso em: 15 maio 2018.

SLEBODNIK, Maribeth; RIEHLE, Catherine Fraser. Creating Online Tutorials at Y our Libraries 
Software Choices and Practical Implications. Libraries Faculty and Staff Scholarship and Research, v. 49, n. 1, 2011. Disponível em: <http://docs.lib.purdue.edu/lib fsdocs/18>. Acesso em: 27 maio 2019.

SOUZA, Francisco das Chagas de. Os paradigmas da Biblioteconomia e suas implicações no ensino desta ciência. Encontros Bibli: Revista Eletrônica de Biblioteconomia e Ciência da Informação, v. 1, n. 2, p. 1-8, 1996.

SUAIDEN, Emir José. A biblioteca pública no contexto da sociedade da informação. Ciência da Informação, Brasília, v. 29, n. 2, p. 52-60, maio/ago. 2000. Disponível em: <http://www.scielo.br/pdf/ci/v29n2/a07v29n2.pdf $>$. Acesso em: 16 ago. 2019.

TARAPANOFF, Kira; ARAÚJO JUNIOR, Rogério Henrique de; CORMIER, Patricia Marie Jeanne. Sociedade da informação e inteligência em unidades de informação. Ciência da informação, Brasília, v. 29, n. 3, p. 91-100, set./dez. 2000. Disponível em: <http://www.scielo.br/pdf/ci/v29n3/a09v29n3.pdf>. Acesso em: 15 abr. 2018.

TAYLOR, Robert. Value-added process in information systems. Norwood: Abley Publishing, 1986.

TOFFLER, Alvin. A terceira onda.7. ed. Rio de Janeiro: Record, 2003.

VASSILAKAKI, Evgenia; GAROUFALLOU, Emmanuel. The impact of Twitter on libraries: a critical review of the literature. The Electronic Library, v. 33, n. 4, p. 795-809, 2015. Disponivel em: $<$ https://www.emeraldinsight.com/doi/full/10.1108/EL-03-2014-0051>. Acesso em: 23 maio 2019.

VERGARA, Silvia. Projetos e relatórios de pesquisa em administração. 8. ed. São Paulo: Atlas, 2007.

VIERA, Angel Freddy Godoy; VARVAKIS, Gregório; FORESTI, Fabricio. Perspectivas e desafios dos dispositivos móveis para as bibliotecas universitárias brasileiras. Revista Interamericana de Bibliotecología, v. 41, n. 1, 2017. Disponível em: <https://aprendeenlinea.udea.edu.co/revistas/index.php/RIB/article/view/330639/20786951 > . Acesso em: 3 maio 2019. 